This is an electronic reprint of the original article. This reprint may differ from the original in pagination and typographic detail.

\author{
Author(s): Loukola, Olli; Seppänen, Janne-Tuomas; Krams, Indrikis; Torvinen, Satu; Forsman, \\ Jukka
}

Title: $\quad$ Observed Fitness May Affect Niche Overlap in Competing Species via Selective Social Information Use

Year: $\quad 2013$

Version:

Please cite the original version:

Loukola, O., Seppänen, J.-T., Krams, I., Torvinen, S., \& Forsman, J. (2013). Observed Fitness May Affect Niche Overlap in Competing Species via Selective Social Information Use. The American Naturalist, 182(4), 474-483.

https://doi.org/10.1086/671815

All material supplied via JYX is protected by copyright and other intellectual property rights, and duplication or sale of all or part of any of the repository collections is not permitted, except that material may be duplicated by you for your research use or educational purposes in electronic or print form. You must obtain permission for any other use. Electronic or print copies may not be offered, whether for sale or otherwise to anyone who is not an authorised user. 


\section{CHICAGO JOURNALS}

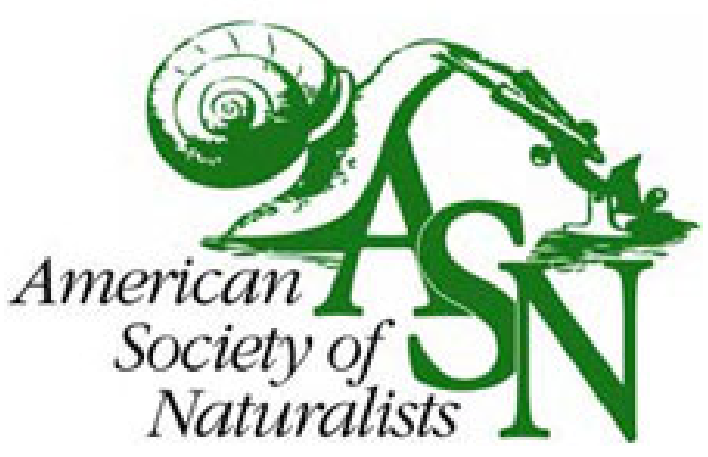

The University of Chicago

Observed Fitness May Affect Niche Overlap in Competing Species via Selective Social Information Use.

Author(s): Olli J. Loukola, Janne-Tuomas Seppänen, Indrikis Krams, Satu S. Torvinen, and Jukka T. Forsman

Source: The American Naturalist, Vol. 182, No. 4 (October 2013), pp. 474-483

Published by: The University of Chicago Press for The American Society of Naturalists

Stable URL: http://www.jstor.org/stable/10.1086/671815

Accessed: 07/02/2014 04:24

Your use of the JSTOR archive indicates your acceptance of the Terms \& Conditions of Use, available at http://www.jstor.org/page/info/about/policies/terms.jsp

JSTOR is a not-for-profit service that helps scholars, researchers, and students discover, use, and build upon a wide range of content in a trusted digital archive. We use information technology and tools to increase productivity and facilitate new forms of scholarship. For more information about JSTOR, please contact support@ jstor.org. 


\title{
Observed Fitness May Affect Niche Overlap in Competing Species via Selective Social Information Use
}

\author{
Olli J. Loukola, ${ }^{1, \star}$ Janne-Tuomas Seppänen, ${ }^{2}$ Indrikis Krams, ${ }^{3}$ Satu S. Torvinen, ${ }^{1}$ and \\ Jukka T. Forsman ${ }^{1}$ \\ 1. Department of Biology, University of Oulu, P.O. Box 3000, 90014 Oulu, Finland; 2. Department of Biological and Environmental \\ Science, University of Jyväskylä, P.O. Box 35, 40014 Jyväskylä, Finland; 3. Institute of Systematic Biology, University of Daugavpils, \\ 5401 Daugavpils, Latvia; and Institute of Ecology and Earth Sciences, University of Tartu, 51014 Tartu, Estonia
}

Submitted January 16, 2013; Accepted May 3, 2013; Electronically published August 23, 2013

Online enhancement: appendix, video. Dryad data: http://dx.doi.org/10.5061/dryad.f22m3.

\begin{abstract}
AвSTRACT: Social information transmission is important because it enables horizontal spread of behaviors, not only between conspecifics but also between individuals of different species. Because interspecific social information use is expected to take place among species with similar resource needs, it may have major consequences for the emergence of local adaptations, resource sharing, and community organization. Social information use is expected to be selective, but the conditions promoting it in an interspecific context are not well known. Here, we experimentally test whether pied flycatchers (Ficedula hypoleuca) use the clutch size of great tits (Parus major) in determining the quality of the observed individual and use it as a basis of decision making. We show that pied flycatchers copied or rejected a novel nest site feature preference of great tits experimentally manipulated to exhibit high or low fitness (clutch size), respectively. Our results demonstrate that the social transmission of behaviors across species can be highly selective in response to observed fitness, plausibly making the phenomenon adaptive. In contrast with the current theory of species coexistence, overlap between realized niches of species could dynamically increase or decrease depending on the observed success of surrounding individuals.
\end{abstract}

Keywords: character displacement, functional diversity, interspecific competition, social information use, species interactions.

\section{Introduction}

Social transmission of behaviors via parental effects and ecological and cultural inheritance has proven to be such a pervasive phenomenon in animals (Danchin et al. 2004; Dall et al. 2005; Seppänen et al. 2007) that it has raised a call for an extended evolutionary synthesis (Danchin et al. 2011). Cultural inheritance of behaviors through social information use or learning in an intraspecific context is com-

* Corresponding author; e-mail: olli.loukola@oulu.fi.

Am. Nat. 2013. Vol. 182, pp. 474-483. (C) 2013 by The University of Chicago. 0003-0147/2013/18204-54403\$15.00. All rights reserved.

DOI: $10.1086 / 671815$ mon in the animal kingdom (Danchin et al. 2004). It has been found to affect various important aspects of animal behavior, such as choice of mates, food, foraging, breeding sites, and nest site features (reviewed in Seppänen et al. 2007), and therefore can potentially modify selection pressure and influence genetic evolution (Danchin et al. 2011).

Social information use is not limited to within-species contexts. A growing number of studies suggest that social information use can also take place among heterospecific individuals (e.g., Mönkkönen et al. 1990; Coolen et al. 2003; Thomson et al. 2003; Seppänen and Forsman 2007; Slagsvold and Wiebe 2011). The prevalence of interspecific social information use is predicted to increase with increasing niche overlap up to a level when costs of competition outweigh the benefits of information (Seppänen et al. 2007). In other words, putatively competing species can act as a source of social information, which can bring about positive net effects to some or all of the involved parties (Forsman et al. 2002; Seppänen et al. 2007; Goodale et al. 2010). However, very little is known about the mechanisms of social transfer of behavior in the interspecific context and its implications for species interactions and coexistence.

If social information use involves adoption of observed behaviors of another species, it increases overlap in behavior-and consequently overlap in resource use between the observer and individual being observed. Hence, the predictions of interspecific social information use are in sharp contrast with the tenet of species coexistence, which states that natural selection should lead to divergence of traits, such as behavior, habitat use, and morphology, among species using similar resources (Pianka 1966; MacArthur and Levins 1967; Schoener 1974; Schluter 2000). For example, interspecific competition has been shown to limit the foraging niches of an arboreal feeding guild of passerine birds (Alatalo et al. 1987). In contrast, interspecific social information use predicts that increasing ecological similarity 
should further facilitate the value of information (Seppänen et al. 2007), and if costs of increasing competition do not exceed the benefits derived from the social information use, then a force maintaining or increasing ecological similarity may exist in many animal communities.

Understanding the conditions and consequences of within-community social information use requires manipulative field experiments (Beltman et al. 2004; Galef 2004; Thornton and Clutton-Brock 2011). These, however, have rarely been conducted (Reader and Biro 2010) because of the challenges of arranging controlled conditions. In addition, strong inference also requires that the examined context is ecologically relevant while genetically inherited or asocial learning mechanisms can be controlled for. We achieve this by creating, in an ecologically relevant context, an appearance of a neutral, novel behavior that can be readily perceived, cross controlled, manipulated, and replicated in the wild. The observing individual is forced to choose between nesting sites differing only with respect to associated geometric symbols, while an experimentally induced and randomly assigned appearance of choice toward one of the symbols is exhibited by a nearby, previously settled heterospecific (Seppänen and Forsman 2007; Forsman and Seppänen 2011; Seppänen et al. 2011; Loukola et al. 2012). If there is a response to these biologically neutral stimuli as a consequence of observing heterospecific behavior, then the existence and implications of interspecific social information use in nature are strongly inferred.

The examined behavioral trait, preference of nest site characteristics, is partially genetically determined (Jaenike and Holt 1991; Slagsvold et al. 2013). It is also an important element of ecological niche in birds and can be under divergence because of increasing costs of nest predation for individuals that overlap with coexisting species in terms of nest site characteristics (Martin 1996). Yet two migratory flycatcher species (Ficedula albicollis, Ficedula hypoleuca) seem to be sensitive to nest site choices and performance of competing resident tits: they tend to copy the tit's choice when arriving late (Seppänen and Forsman 2007) or the choice of those tits with naturally large clutches (Seppänen et al. 2011), and they clearly reject a novel preference exhibited by tits with naturally small clutch sizes (Forsman and Seppänen 2011; Seppänen et al. 2011). Flycatchers also increase breeding investment when nesting near territories of tits that have relatively large clutches (Forsman et al. 2012). However, the evidence gathered to date about selective information use relative to fitness of the observed individual is inconclusive and open to alternative explanations: the study showing response in copying (Seppänen et al. 2011) did not manipulate the clutch size of the tits, so the response could have been to, for example, tit parent phenotype, habitat quality, or the amount of food rather than to observable clutch size directly. An experiment with artificial tit nests and eggs (Forsman and Seppänen 2011) implied a rejection response to observing small clutches but was not able to demonstrate copying. Experiments that specifically manipulate correlates of fitness of the observed individuals and measure observers' behavior are therefore needed.

Here, we explicitly test with a manipulative field experiment whether pied flycatchers ( $F$. hypoleuca) use the clutch size of great tits (Parus major) as a basis of decision making. Flycatchers frequently visit tit nest boxes during the period of nest site selection, before the hatching of tit chicks (O. J. Loukola, unpublished data; see also video 1, available online), even when empty nest boxes are abundantly available. Flycatchers also visit tit nest boxes after the hatching of tit nests (Forsman and Thomson 2008). Great tits regularly kill intruding pied flycatchers in our study populations (O. J. Loukola, personal observation; Merilä and Wiggins 1995), suggesting that entering occupied great tit nests conveys some benefit sufficient to outweigh the risk of injury or death. In contrast to earlier works (Forsman and Seppänen 2011; Seppänen et al. 2011), here we manipulated the clutch sizes of freely breeding wild tits. We test whether pied flycatcher choice between two new neutral behaviors (choosing a nest site with one of two alternative geometric symbols) is affected by observing the apparent nest site choice and manipulated fitness (clutch size: 5 or 13 eggs) of great tits (fig. 1; see "Methods"). Copying the behaviors of others is expected to be adaptive only when it is selective (Boyd and Richerson 1985; Henrich and Gil-White 2001; Laland 2004; Ken-

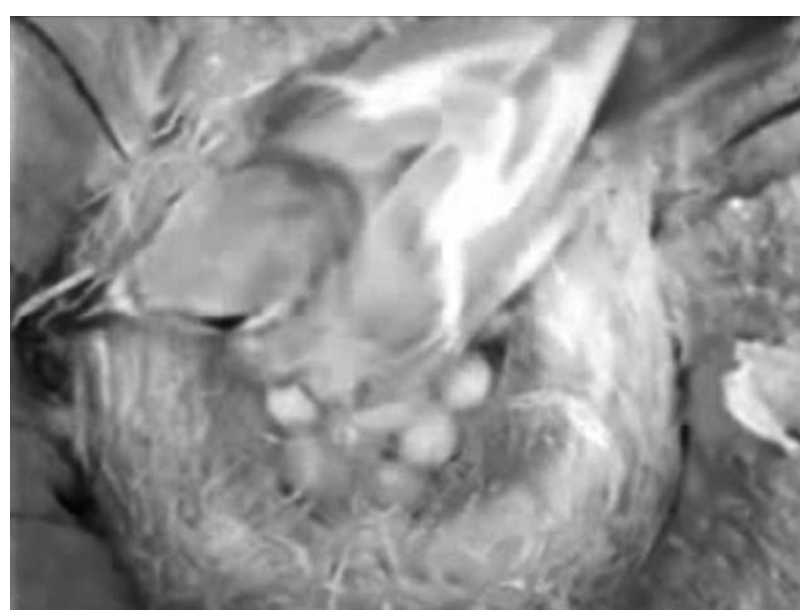

Video 1: Still photograph from a video (video 1, available online) depicting a pied flycatcher pair inspecting an active tit nest. The flycatcher male is attracting the female inside the tit nest. The female can be seen to repeatedly rub the ventral area against the tit clutch in various angles. Video by J. Lahdenniemi. 




Figure 1: Experimental setup and locations of study sites.

dal et al. 2005). On the basis of these earlier theoretical works and an earlier study with the same experimental design but without the manipulation of clutch size (Seppänen et al. 2011), we predicted that flycatcher choices should more often match with tits having a high fitness correlate (clutch size), while behavior of tits with a poor fitness correlate should be actively rejected.

\section{Methods}

\section{Experimental Setup}

The experiments were conducted in mixed and coniferous forests in Finland near the city of Oulu and in Latvian pine plantation forests near the city of Daugavpils during the spring of 2011. Nest boxes for great tits were distributed a few weeks before tits initiate nest building along small roads throughout the study area, and tits were allowed to settle freely. The sizes of the study areas were approximately $160 \mathrm{~km}^{2}$ in Oulu and $185 \mathrm{~km}^{2}$ in Daugavpils and contained 148 separate experimental setups altogether (84 in Oulu and 64 in Latvia).

When tits initiated nest building, nests were randomly assigned to either 5- or 13-egg manipulation. The clutch sizes corresponded to the observed minimum and maximum in these areas. In the 5-egg manipulation, eggs after the first 5 were removed daily from the nest when the female was not present. The removed eggs were added to nests in the 13-egg manipulation. Clutch size manipulation continued until female tits started incubation. Once the assigned clutch size was reached, the tit nest box was marked with a randomly assigned symbol, either a white circle or a triangle ( $7.5 \mathrm{~cm}$ diameter or sides), attached at the nest box entrance $(3.2 \mathrm{~cm}$ diameter). The front of the boxes was painted black to contrast with the white plastic symbols. An empty nest box with the opposite symbol was added on the nearest similar tree (2-6 $\mathrm{m}$ away) to create the appearance that the tit had had a choice between the two alternatives. Boxes were so close that tits aggressively defended both, preventing flycatchers from settling in the vacant box. At approximately $25 \mathrm{~m}$ distance from this first pair, two empty boxes facing the first pair were added on adjacent similar trees for the arriving flycatcher, with the alternative symbols randomly assigned to left and right. These four boxes comprised one setup (fig. 1). The setups were at least a kilometer apart to reduce the chances of flycatcher females responding to symbols of other experimental setups.

\section{Measurements}

Nest boxes were inspected every day, and flycatcher choices and dates were determined by the appearance of nest material. Some great tits cover eggs with nest material during 
Finland: young females
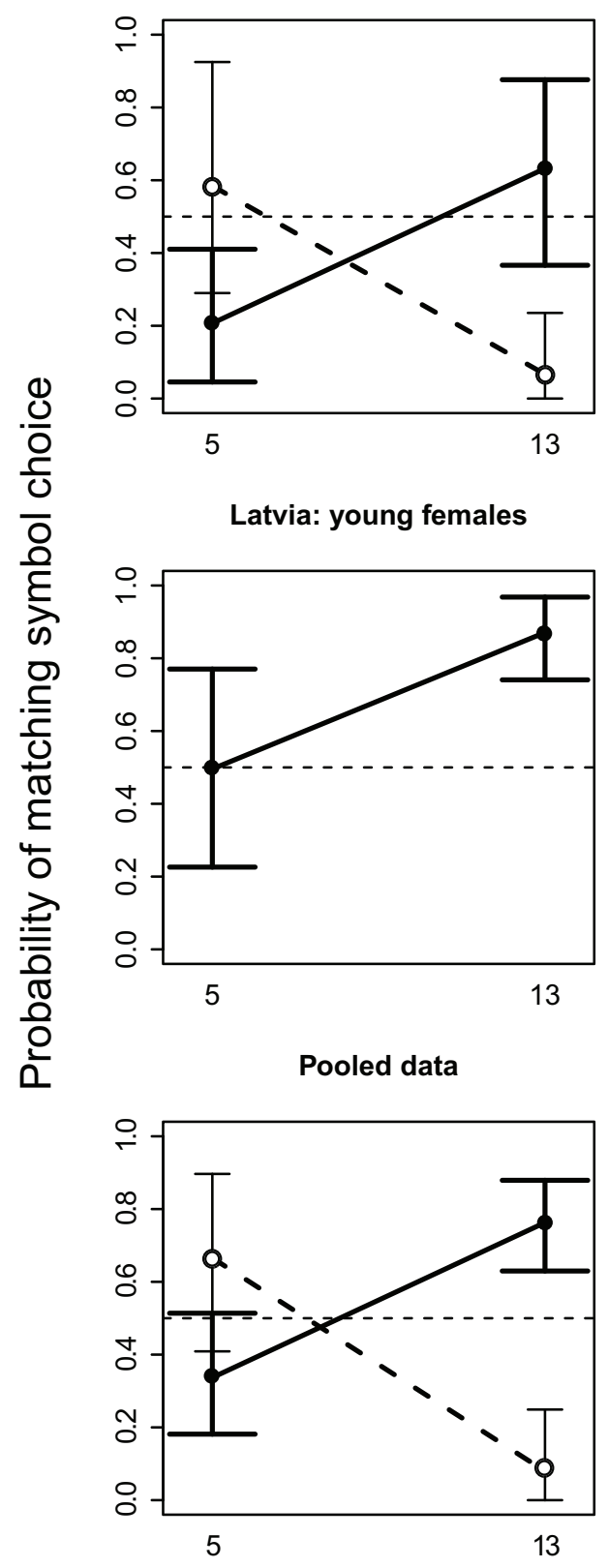

Finland: old females

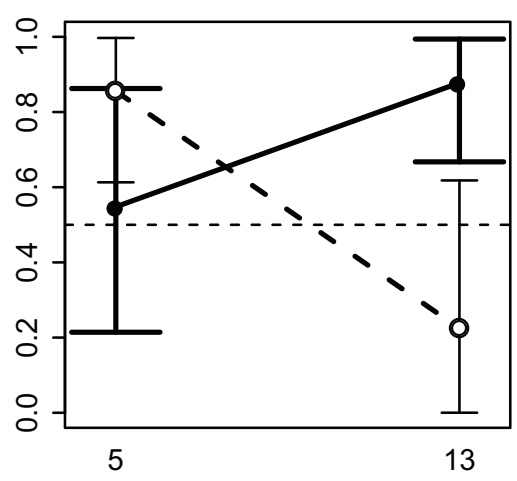

Latvia: old females

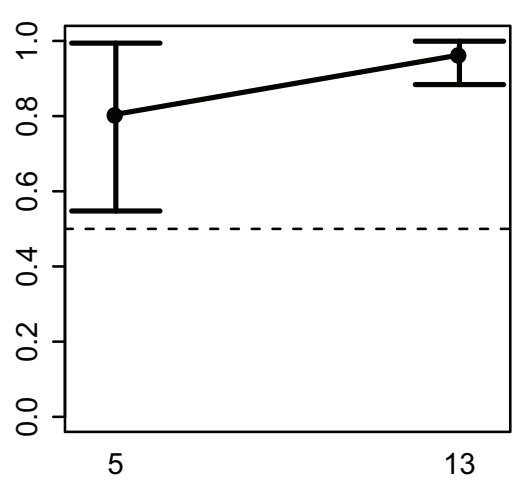

\section{Tit clutch size}

Figure 2: Probabilities of pied flycatchers copying the symbol choices of great tits in the two treatments. Filled and open circles represent the mean probabilities that flycatchers choose nest boxes with a symbol matching the one on the great tit's nest box when clutch size information is and is not available, respectively. Bars represent $95 \%$ highest posterior density credibility intervals. Solid and dashed lines illustrate the interaction between tit clutch size manipulation and information availability. Probability of 0.5 corresponds to random choice.

laying (see figs. B1, B2, available online). We therefore also recorded whether the tit clutch was covered. Adult pied flycatchers were captured when chicks were 13 days old by using passive nest box traps and phenotype measure- ments (age, sex, and length of tarsus) were collected. Age was classified in the field and later ensured from the photographs of the wing and tail feathers, after which individuals were classified as juveniles (first-time breeders) or 
Table 1: Parameter estimates of the definitive generalized linear model

\begin{tabular}{lrcc}
\hline Variable & Estimate & SE & $P$ \\
\hline Intercept & -1.152 & .539 & .033 \\
Treatment (13 eggs) & 1.665 & .594 & .005 \\
IA (not available) & 1.472 & .804 & .067 \\
Area (Latvia) & 1.161 & .590 & .049 \\
FH_F_AGE (old) & 1.350 & .701 & .054 \\
Treatment (13 eggs): IA (not & & & \\
$\quad$ available) & -4.515 & 1.472 & .002 \\
\hline
\end{tabular}

Note: Residual deviance: 91.106 on 79 df. IA = information availability, FH_F_AGE = age of the flycatcher female.

adults (at least 2 years old; Jenni and Winkler 1994). In the experiment reported here, each flycatcher pair observed one breeding tit pair exhibiting the preference.

\section{Statistical Analysis}

All analyses were done using R (ver. 2.15.1; R Development Core Team 2012). Generalized linear models (function "glm") were fitted to determine variables that significantly predicted the symbol choice of pied flycatcher pair (binary variable: $1=$ matching and $0=$ opposing the symbol on the great tit's nest box). The full model included treatment ( 5 or 13 eggs), clutch size information availability $(1=$ eggs visible and uncovered, $0=$ eggs covered), area (Finland or Latvia), date of the choice, symbol on the tit nest, phenotype measurements of flycatchers (age, sex, and length of tarsus), and the interaction between manipulation and clutch size information availability as explanatory variables. The data on age of the male flycatcher and length of tarsus were lacking many observations and furthermore did not have a main effect here; thus, they were not included in model comparisons because of overparameterization. It was possible to analyze the effect of male age without other variables in the same models, and its main effect was not statistically significant. The full model was compared with simpler models, and the model with the smallest Akaike's Information Criterion value (Akaike 1974) was used in inferences (see table A1). Treatment, availability of clutch size information, and the interaction between these two explanatory variables were retained in all models because of their ecological relevance to the question.

To derive confidence intervals for the fitted probabilities of flycatchers choosing the tit symbol in both study areas and tit clutch size treatments, we reran the final model with a Bayesian approach based on Markov chain Monte Carlo (MCMC) simulations (function "MCMCglmm"; Hadfield 2010). We also repeated the Bayesian analysis for pooled data (both areas and all choices together). All
MCMC simulations were run for 15,000,000 iterations with a burn-in phase of 5,000,000 iterations and a thinning interval of 10,000. We derived posterior distributions for all combinations of categorical explanatory variables included in the final model from the fixed effects, as well as for pooled data (see fig. 2). We then back-transformed the posterior distributions attained in this way to the scale of observations (i.e., probabilities) and determined their 95\% highest posterior density credibility intervals (function "HPDinterval"; Plummer et al. 2006).

\section{Results}

A total of 111 nest box choices of pied flycatcher pairs were measured (68 in Finland and 43 in Latvia; data available from the Dryad Digital Repository, http://dx.doi.org /10.5061/dryad.f22m3 [Loukola 2013]). The rest of the setups, in which the tits abandoned their nest before the flycatchers' arrival or in which no flycatchers settled (16 in Finland and 21 in Latvia), were not included in the analysis. In Oulu 27 tit pairs covered their eggs during the whole period of flycatchers' nest site selection, while in Daugavpils all tit pairs were incubating, and observable clutch size information was available by the time flycatchers arrived.

Parameter estimates of the definitive generalized linear model are presented in table 1 , and the Bayesian highest posterior density $95 \%$ confidence intervals for flycatcher choice estimates depending on treatment, information availability, and flycatcher female age are presented in figure 2 (the exact values are presented in table A2). The clutch size manipulation (treatments: 5 or 13 eggs in tit nest) of the great tit pair explained the symbol choice match of the pied flycatcher pair. In the 13-egg treatment flycatchers copied and rejected tit symbols 36 and 22 times, respectively, while in the 5-egg treatment they copied and rejected them 24 and 29 times, respectively. However, there was a strong interaction between tit clutch size manipulation and information availability (table 1; fig. 2). This was because the probability that flycatchers copied the tit symbol increased for the 13-egg treatment size when the clutch size information was available, whereas the response was the opposite when clutch size information was not available. Moreover, old females had a higher probability of copying tit symbols than did young females (table 1; fig. 2).

Flycatcher choices in those setups where the information was available (84 setups) are presented in figure 3. Flycatchers strongly copied symbol choices of tits with high clutch sizes and tended to reject choices of tits with low clutch sizes if clutch size information was available because of uncovered eggs. 


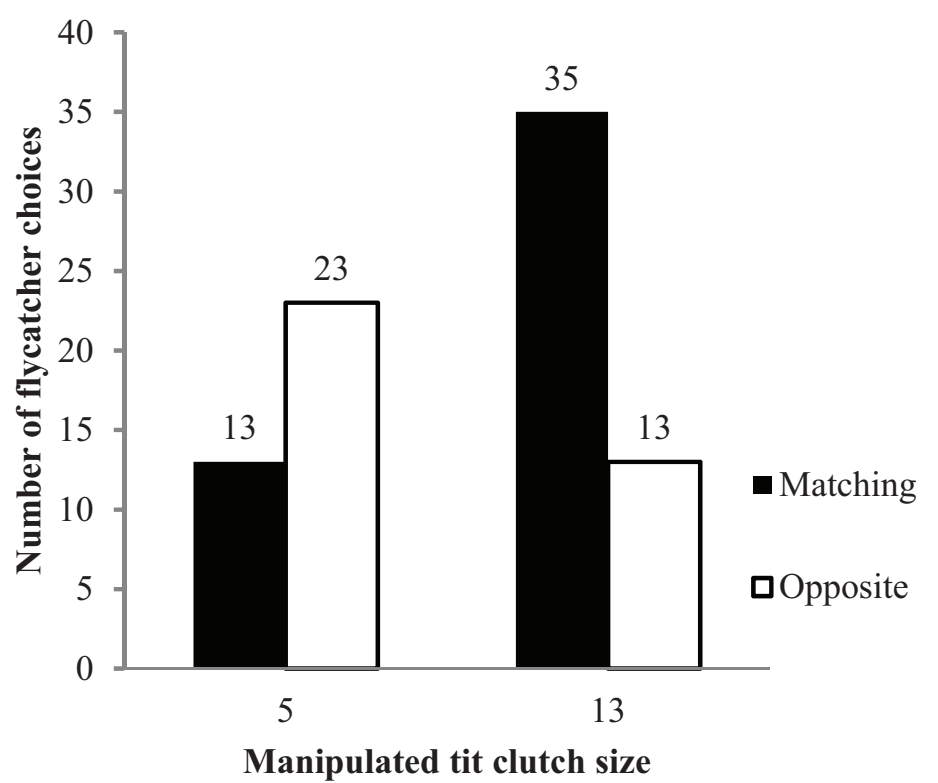

Figure 3: Nest site feature choices of pied flycatchers when clutch size information is available. Black bars denote flycatcher nests in nest boxes with a symbol matching the one on the great tit's nest box, and white bars denote flycatcher nests in nest boxes with an opposite symbol.

\section{Discussion}

Our results from two distant study areas $(>1,000 \mathrm{~km})$ provide conclusive experimental evidence of response to perceived fitness in interspecific social information use. In general, pied flycatchers copied a novel nest site feature preference of great tits experimentally manipulated to exhibit high fitness (clutch size) and tended to choose the opposite alternative if the great tit nest exhibited low fitness. Our results are in line with both the findings of an earlier correlative study (Seppänen et al. 2011) and the results of an experiment with artificial tit nests and eggs (Forsman and Seppänen 2011) and suggest that selective interspecific information use based on fitness of the observed individuals exists in the wild.

There are two significant findings in this study proving that flycatchers use perceived fitness (clutch size) of the observed individuals as a primary cue of whether to copy or reject observed novel behavior. First, by manipulating the amount of eggs in tit nests in the wild, we excluded the alternative explanations that might influence flycatcher decisions, such as the effect of tit parent phenotype, habitat quality, or the amount of food. Second, we found that if tit clutch size information was not available for flycatchers because of covered eggs, flycatchers tended to make opposite choices compared with the situation when a clutch was not covered (in particular in the high-clutch-size treatment). A plausible explanation might be that clutch size manipulation caused changes in the behavior of tits, such as increasing aggression or boldness, which in turn affected the flycatcher choices. The mechanism behind these possible changes in the behavior of tits due to manipulation is still unknown, but Allander (1997), for example, found that fitness manipulation caused phenotypic responses in great tit parents in terms of prevalence of protozoan blood parasites.

The flycatcher response was slightly different between the study areas. Flycatchers' preference to copy tits with large clutches was stronger in Latvia than in Finland, but rejection of the behavior exhibited by tits with small clutches was not significant. However, in the 5-egg treatment in Latvia, only 44\% (14/32) of available setups were occupied by flycatchers, while occupation rates in the 13egg treatment in Latvia and in both treatments in Finland were much higher $(>80 \%)$. This suggests that most Latvian flycatchers may have rejected the broader location choice of tits perceived to be unsuccessful, and those that did settle there were plausibly less likely to respond to observed poor performance in smaller-scale decisions either. One possible explanation for a higher flycatcher occupancy rate near tit nests with large clutches is an antipredator strategy. For example, if great tits increase their alarm call rate with increasing clutch size when a potential nest predator is present, as Acadian flycatchers (Empidonax virescens) do (Olendorf and Robinson 2000), then pied flycatchers should garner a larger antipredator benefit when nesting close to tits with large clutches. In addition, we found that old females had a higher probability of copying tit symbols than did young females. According to recent study by 
Forsman et al. (2012), old females are probably more experienced in evaluating clutch size and its range than young females. However, our results indicate that older females appear to copy the tits regardless of their observed clutch size and that tit clutch size has more weight in the decision-making process of young females.

A recent study by Cole et al. (2012) provides a compelling reason why clutch-size-sensitive selective social information use may be adaptive and why even novel adaptively neutral preference to geometric symbols can be transferred: the authors showed that female great tits with good problem-solving skills produced larger clutches in smaller foraging ranges and with shorter workday lengths than did nonsolver females, regardless of the quality of nesting habitat. For prospecting flycatchers, clutch size of tits does not necessarily indicate a superior choice directly but reveals competence of the observed individual in decision making. While able to observe and copy, flycatchers are, of course, not able to discern whether an observed tit behavior is simply a species trait, a local adaptation, or an individually learned preference or technique, let alone whether and how a particular behavior might affect fitness. But if the perceived high fitness is a reliable indicator that the tit's choices are on average better than a random choice, then any behavior, even a totally novel one that in reality is biologically neutral (such as preference for a symbol on the entrance of the nest box), should be copied-as is demonstrated here. Conversely, if poor breeding success is a reliable indicator that the tit has poor cognitive abilities, makes poor decisions, and possesses suboptimal learned behaviors (Cole et al. 2012), then active rejection of the behaviors of that individual is better than simply ignoring the information.

An actively selective strategy to either copy or reject behavior of other species based on perceived fitness of the observed individual can have major consequences for niche overlap and resource partitioning. One of the central paradigms of evolutionary ecology, competition theory, postulates that two species with overlapping niches should be negatively impacted by the presence of the other due to competition, which in turn should lead to character displacement (Brown and Wilson 1956), niche segregation, and avoidance (MacArthur and Levins 1967; Schoener 1974; Schluter 2000). Social information use strategies sensitive to perceived fitness of the observed individual make niche overlap a more behaviorally and ecologically dynamic phenomenon than assumed by competition theory. Niche overlap should be increased by selective social information use toward the most successful individuals or in favorable environmental conditions that enhance the perceived fitness of the observed individuals. Conversely, active rejection of behaviors of poorly performing individuals can increase niche segregation and reduce costs of competition relative to the least successful individuals and in poor environmental conditions. Selective social information use leading to dynamic adjustment of niche overlap in response to community composition and availability of resources and information may allow invasion or coexistence of more ecologically similar species than would otherwise be possible. In addition, these dynamics may indirectly affect genetic evolution.

Interspecific information use may also entail costs for the individuals being observed (Forsman et al. 2007), potentially leading to arms races between attempts to acquire information and strategies to prevent information use. The options for the parasitized individual, such as tits here, are to cease providing information, if possible; to attempt (e.g., by aggression) to close the window of profitable information use (Seppänen et al. 2007); or to attempt to hide the event spied by the information parasite. As this study shows, egg-covering behavior of tits indeed affects the nest site decisions of pied flycatchers. We may also speculate that if tits that covered eggs did so to counter flycatcher information use, they were also more likely to exhibit other behaviors, such as aggression, to deter copying, resulting in young flycatcher females avoiding the observed tit symbol choice at egg-covered sites (fig. 2).

Selective social information use may help us understand patterns of and interactions between organization, species richness, and functional diversity of communities. For example, competition theory predicts that, because of competitive exclusion, more diverse communities are more difficult to invade and functional diversity should be larger than that expected by chance. In contrast, selective copying and dynamic adjustment of niche overlap by social information use give the opposite predictions. Indeed, in birds there is little evidence for the biotic invasion resistance hypothesis (Duncan et al. 2003), and the functional diversity of avian assemblages (Petchey et al. 2007) and mixed-species flocks (Sridhar et al. 2012) is often lower than that expected by chance.

We propose that fitness-sensitive social information use, including active rejection of observed behavior, is potentially a general and common phenomenon in nature and may occur in any animal community where individuals' fitness correlates (clutch, litter, or brood size; condition of the offspring; etc.) are publicly observable. There is evidence that animals ranging from insects to vertebrates can perceive and respond to the observed offspring investment or success of others (Doligez et al. 2002; Parejo et al. 2005; Fletcher and Miller 2008). Why this phenomenon has gone unnoticed before is perhaps because rejection of the behavior of an observed individual performing poorly is in apparent accordance with character displacement and avoidance and because when both copying and rejection occur there might be no obvious population-level patterns 
despite strong effects, as well as the difficulty in arranging controlled experimental designs.

Our results reveal that novel behavior can traverse species boundaries, potentially having the same effect as innovation, an important component of behavioral flexibility and cultural evolution (Reader and Laland 2003). This has many important implications. For example, local adaptations could arise from interspecific transmission of behavior more rapidly and frequently than would be expected by intraspecific processes alone. As a result, individuals of species capable of acquiring locally adaptive or rejecting nonadaptive behaviors from other species could be predisposed to invade new regions. Conversely, disruptions of transmission opportunities or a natural lack of this capacity could make a species more vulnerable to environmental change. Furthermore, while the results presented here do not yet demonstrate cultural transmission of behaviors across years or generations, it is nonetheless interesting to note that selective and discriminating social information use is suggested to be crucial for cumulative culture to evolve (Henrich and Gil-White 2001; Enquist and Ghirlanda 2007). Determining whether adopting and rejecting behaviors of other species influences behavior and resource use across generations and results in emergence of community-wide patterns is a fascinating challenge for future studies.

\section{Acknowledgments}

We thank T. Jaakkonen, P. Niemelä, and J. Raitanen for critical discussion and reading of the manuscript; V. Hyöky for helping in the field; S. Kivelä for critical discussion and providing valuable help in the statistics; and an anonymous reviewer in the Peerage of Science community for valuable comments on an early version of the manuscript. In addition, we thank T. Slagsvold and an anonymous reviewer for comments that helped us make significant improvements to the final version of the manuscript. We also thank J. Lahdenniemi for allowing us to use the video. O.J.L. is funded by the Biological Interactions Graduate School, J.T.F. is funded by the Academy of Finland (grants 122665 and 125720), and J.-T.S. is funded by the Academy of Finland (grant 252818). Research was carried out in accordance with Finnish and Latvian legislation. All authors declare they have no actual or potential competing financial interest.

\section{APPENDIX A}

Table A1: Akaike's Information Criterion (AIC) model selection results for logistic regression analysis of factors affecting flycatchers' symbol choices

\begin{tabular}{|c|c|c|c|c|}
\hline Model (glm) & $\begin{array}{l}\text { No. } \\
\text { parameters }\end{array}$ & AIC & $\Delta \mathrm{AIC}$ & $\begin{array}{c}\text { Akaike } \\
\text { weight }\left(w_{i}\right)\end{array}$ \\
\hline $\begin{array}{l}\text { Choice } \sim \text { manipulation } \times \text { IA }+ \text { area }+ \text { date }+ \text { tit nest symbol }+ \text { age of } \\
\text { the flycatcher female }\end{array}$ & 8 & 106.242 & 3.136 & .106 \\
\hline Choice $\sim$ manipulation $\times$ IA + area + date + tit nest symbol & 7 & 142.212 & 39.106 & .000 \\
\hline Choice $\sim$ manipulation $\times$ IA + area + date & 6 & 140.330 & 37.224 & .000 \\
\hline Choice $\sim$ manipulation $\times$ IA + area & 5 & 138.376 & 35.271 & .000 \\
\hline Choice $\sim$ manipulation $\times$ IA & 4 & 139.740 & 36.635 & .000 \\
\hline Choice $\sim$ manipulation $\times$ IA + area + date + age of the flycatcher female & 7 & 105.049 & 1.943 & .193 \\
\hline Choice $\sim$ manipulation $\times$ IA + area + age of the flycatcher female & 6 & 103.106 & .000 & .511 \\
\hline Choice $\sim$ manipulation $\times$ IA + age of the flycatcher female & 5 & 105.087 & 1.981 & .190 \\
\hline
\end{tabular}

Note: Akaike weights $\left(w_{i}\right)$ represent the strength of evidence in favor of model $i$ being the best model. IA $=$ information availability.

Table A2: The Bayesian highest posterior density (HPD) 95\% confidence intervals for flycatcher pairs' (with young and old females) symbol choice estimates when clutch size information was and was not available

\begin{tabular}{lccccc}
\hline & $\begin{array}{c}\text { Treatment } \\
\text { D } 5 \text { or } 13 \text { eggs })\end{array}$ & $\begin{array}{c}\text { Information } \\
\text { available }\end{array}$ & 95\% HPD & $\begin{array}{c}\text { Proportion } \\
\text { copying }\end{array}$ & $\begin{array}{c}\text { Posterior } \\
\text { probability } \\
\text { of copying }\end{array}$ \\
\hline Finland, young females & 5 & Yes & $.05-.41$ & .21 & .18 \\
Finland, young females & 5 & No & $.29-.93$ & .58 & .59 \\
Finland, young females & 13 & Yes & $.37-.88$ & .63 & .65 \\
Finland, young females & 13 & No & $.00-.24$ & .07 & .95 \\
Finland, old females & 5 & Yes & $.21-.86$ & .54 & .49
\end{tabular}


Table A2 (Continued)

\begin{tabular}{lccccc}
\hline & $\begin{array}{c}\text { Treatment } \\
\text { (5 or } 13 \text { eggs) }\end{array}$ & $\begin{array}{c}\text { Information } \\
\text { available }\end{array}$ & 95\% HPD & $\begin{array}{c}\text { Proportion } \\
\text { copying }\end{array}$ & $\begin{array}{c}\text { Posterior } \\
\text { probability } \\
\text { of copying }\end{array}$ \\
\hline Finland, old females & 5 & No & $.61-.99$ & .86 & .90 \\
Finland, old females & 13 & Yes & $.67-.99$ & .87 & .96 \\
Finland, old females & 13 & No & $.00-.62$ & .22 & .01 \\
Latvia, young females & 5 & Yes & $.23-.77$ & .50 & .54 \\
Latvia, young females & 13 & Yes & $.74-.97$ & .87 & .89 \\
Latvia, old females & 5 & Yes & $.55-.99$ & .80 & .94 \\
Latvia, old females & 13 & Yes & $.88-1.00$ & .96 & .99 \\
Pooled data & 5 & Yes & $.18-.52$ & .34 & .29 \\
Pooled data & 5 & No & $.41-.90$ & .67 & .70 \\
Pooled data & 13 & Yes & $.63-.88$ & .76 & .79 \\
Pooled data & 13 & No & $.00-.25$ & .08 & .02 \\
\hline
\end{tabular}

Literature Cited
Fletcher, R. J., Jr., and C. W. Miller. 2008. The type and timing of social information alters offspring production. Biology Letters 4 : $482-485$.

$\rightarrow$ Forsman, J. T., and J.-T. Seppänen. 2011. Learning what (not) to do: testing rejection and copying of heterospecific behavioural trait. Animal Behaviour 81:879-883.

$\rightarrow$ Forsman, J. T., J.-T. Seppänen, and M. Mönkkönen. 2002. Positive fitness consequences of interspecific interaction with a potential competitor. Proceedings of the Royal Society B: Biological Sciences 269:1619-1623.

$\rightarrow$ Forsman, J. T., J.-T. Seppänen, and I. L. Nykänen. 2012. Observed heterospecific clutch size can affect offspring investment decisions. Biology Letters 8:341-343.

$\rightarrow$ Forsman, J. T., and R. L. Thomson. 2008. Evidence of information collection from heterospecifics in cavity-nesting birds. Ibis 150: $409-412$.

$\rightarrow$ Galef, B. G., Jr. 2004. Approaches to the study of traditional behaviors of free-living animals. Animal Learning and Behavior 32:53-61.

$\rightarrow$ Goodale, E., G. Beauchamp, R. D. Magrath, J. C. Nieh, and G. D. Ruxton. 2010. Interspecific information transfer influences animal community structure. Trends in Ecology and Evolution 25:354361.

Hadfield, J. 2010. MCMC methods for multi-response generalized linear mixed models: the MCMCglmm R package. Journal of Statistical Software 33:1-22.

$\rightarrow$ Henrich, J., and F. J. Gil-White. 2001. The evolution of prestige: freely conferred status as a mechanism for enhancing the benefits of cultural transmission. Evolution and Human Behavior 22:165196.

Jaenike, J., and R. D. Holt. 1991. Genetic variation for habitat preference: evidence and explanations. American Naturalist 137(suppl.): S67-S90.

Jenni, L., and R. Winkler. 1994. Moult and ageing of European passerines. Academic Press, London.

$\rightarrow$ Kendal, R. L., I. Coolen, Y. V. Bergen, and K. N. Laland. 2005. Tradeoffs in the adaptive use of social and asocial learning. Advances in the Study of Behavior 35:333-379.

$\rightarrow$ Laland, K. N. 2004. Social learning strategies. Animal Learning and Behavior 32:4-14. tematics 34:71-98.

$\rightarrow$ Enquist, M., and S. Ghirlanda. 2007. Evolution of social learnin£ $\rightarrow$ L does not explain the origin of human cumulative culture. Journal of Theoretical Biology 246:129-135.
Loukola, O. J., J.-T. Seppänen, and J. T. Forsman. 2012. Intraspecific social information use in the selection of nest site characteristics. Animal Behaviour 83:629-633. 
Loukola, O. J., J.-T. Seppänen, I. Krams, S. S. Torvinen, and J. T. Forsman. 2013. Data from: Observed fitness may affect niche overlap in competing species via selective social information use. American Naturalist, Dryad Digital Repository, http://dx.doi.org/10 $.5061 /$ dryad.f22m3.

$\rightarrow$ MacArthur, R., and R. Levins. 1967. The limiting similarity, convergence, and divergence of coexisting species. American Naturalis 101:377-385.

$\rightarrow$ Martin, T. E. 1996. Fitness costs of resource overlap among coexisting bird species. Nature 380:338-340.

$\rightarrow$ Merilä, J., and D. A. Wiggins. 1995. Interspecific competition for nest holes causes adult mortality in the collared flycatcher. Condor 97:445-450.

$\rightarrow$ Mönkkönen, M., P. Helle, and K. Soppela. 1990. Numerical ana behavioural responses of migrant passerines to experimental manipulation of resident tits (Parus spp.): hetero-specific attraction in northern breeding bird communities? Oecologia (Berlin) 85: 218-225.

$\rightarrow$ Olendorf, R., and S. K. Robinson. 2000. Effectiveness of nest defence in the Acadian flycatcher Empidonax wirescens. Ibis 142:365-371.

$\rightarrow$ Parejo, D., É. Danchin, and J. M. Avilés. 2005. The heterospecific habitat copying hypothesis: can competitors indicate habitat qual ity? Behavioral Ecology 16:96-105.

$\rightarrow$ Petchey, O. L., K. L. Evans, I. S. Fishburn, and K. J. Gaston. 2007. Low functional diversity and no redundancy in British avian assemblages. Journal of Animal Ecology 76:977-985.

$\rightarrow$ Pianka, E. R. 1966. Convexity, desert lizards and spatial heterogeneity $\rightarrow$ Ecology 47:1055-1059.

Plummer, M., N. Best, K. Cowles, and K. Vines. 2006. CODA: convergence diagnosis and output analysis for MCMC. R News 6:7- $\rightarrow$ 11.

R Development Core Team. 2012. The R project for statistical computing, version 2.15.1. R Foundation for Statistical Computing, Vienna. http://www.r-project.org/.

$\rightarrow$ Reader, S. M., and D. Biro. 2010. Experimental identification of social learning in wild animals. Animal Learning and Behavior 38:265283.
Reader, S. M., and K. N. Laland. 2003. Animal innovation. Oxford University Press, Oxford.

Schluter, D. 2000. The ecology of adaptive radiation. Oxford University Press, Oxford.

$\rightarrow$ Schoener, T. W. 1974. Resource partitioning in ecological communities. Science 185:27-39.

Seppänen, J.-T., and J. T. Forsman. 2007. Interspecific social learning: novel preference can be acquired from a competing species. Current Biology 17:1248-1252.

Seppänen, J.-T., J. T. Forsman, M. Mönkkönen, I. Krams, and T. Salmi. 2011. New behavioural trait adopted or rejected by observing heterospecific tutor fitness. Proceedings of the Royal Society B: Biological Sciences 278:1736-1741.

Seppänen, J.-T., J. T. Forsman, M. Mönkkönen, and R. L. Thomson. 2007. Social information use is a process across space, time and ecology, reaching heterospecifics. Ecology 88:1622-1633.

Slagsvold, T., K. W. Kleiven, A. Eriksen, and L. E. Johannessen. 2013. Vertical and horizontal transmission of nest site preferences in titmice. Animal Behaviour 85:323-328.

Slagsvold, T., and K. Wiebe. 2011. Social learning in birds and its role in shaping a foraging niche. Philosophical Transactions of the Royal Society B: Biological Sciences 366:969-977.

Sridhar, H., U. Srinivasan, R. A. Askins, J. C. Canales-Delgadillo, C. C. Chen, D. N. Ewert, G. A. Gale, et al. 2012. Positive relationships between association strength and phenotypic similarity characterize the assembly of mixed-species bird flocks worldwide. American Naturalist 180:777-790.

Thomson, R. L., J. T. Forsman, and M. Mönkkönen. 2003. Positive interactions between migrant and resident birds: testing the heterospecific attraction hypothesis. Oecologia (Berlin) 134:431-438.

Thornton, A., and T. Clutton-Brock. 2011. Social learning and the development of individual and group behaviour in mammal societies. Philosophical Transactions of the Royal Society B: Biological Sciences 366:978-987.

Associate Editor: Thomas N. Sherratt Editor: Judith L. Bronstein

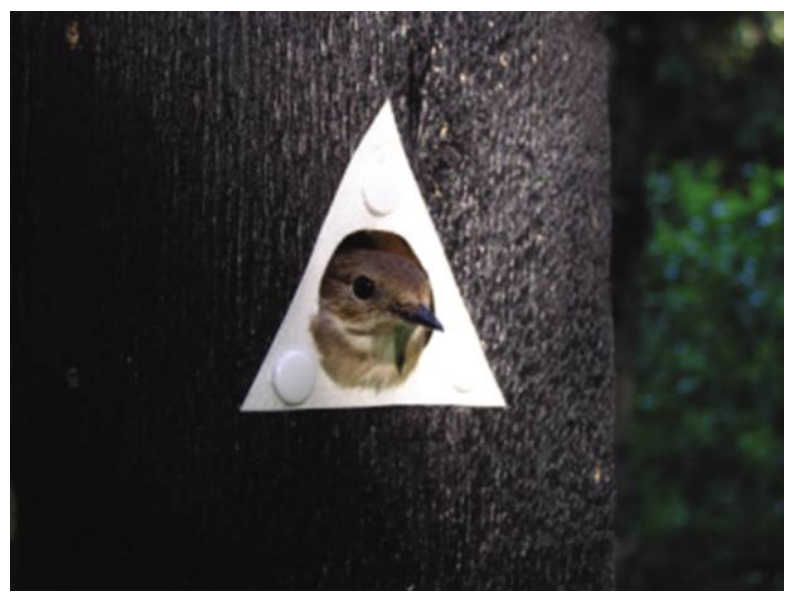

Pied flycatcher (Ficedula hypoleuca) female in the nest box with triangle symbol. Photograph by J.-T. Seppänen. 